\title{
Aspectos comparativos de los hogares con y sin jóvenes en México: una primera aproximación a partir de la información del II Conteo de Población y Vivienda
}

\author{
Patricia Román Reyes* \\ Mauricio Padrón Innamorato**
}

En el presente trabajo se analizan algunas características comparativas de los hogares mexicanos con y sin jóvenes utilizando como fuente de información el II Conteo de Población y Vivienda del año 2005. Se pretende hacer una aportación a los diagnósticos sobre la situación juvenil en México con el propósito de enriquecer la discusión sobre el efecto de las características de conformación de los hogares en las condiciones de vida, de inserción laboral y educativa de la población de 12 a 29 años.

Palabras clave: jóvenes, hogares, familias, composición.

Fecha de recepción: 5 de junio de 2008.

Fecha de aceptación: 28 de octubre de 2008.

Comparative Aspects of Households with and without Youths in Mexico: An Initial Approach on the Basis of Information from the 2nd Population and Housing Survey

This paper analyzes some of the comparative features of Mexican households with and without youths, based on the 2nd Population and Housing Survey. It seeks to contribute to the diagnoses of the youth situation in Mexico to enrich the discussion of the impact that household features have on living conditions, insertion into the job and education market of the population ages 12 to 29.

Key words: youth, households, families, composition.

\section{Introducción}

Tradicionalmente se ha estudiado a los jóvenes desde la perspectiva sociodemográfica en relación con dos variables analíticas centrales: el

* Centro de Investigación y Estudios Avanzados de la Población, Universidad Autónoma del Estado de México. Correo electrónico: promanreyes@yahoo.com.mx.

** Área de Investigación Aplicada y Opinión. Instituto de Investigaciones Jurídicas. Universidad Nacional Autónoma de México. Correo electrónico: mauriciopadron@ gmail.com. 
trabajo y la educación. Así, tanto los problemas, características y condiciones de acceso al mercado de trabajo de la población joven, como sus rezagos y posibilidades educativas, han dominado el ámbito de las investigaciones.

La mayoría de estos trabajos coincide en identificar a los jóvenes como un grupo social en condiciones de vulnerabilidad, exclusión (Pérez Sáinz, 1999; Salvia y Miranda 1997, citados por Gandini, 2004) y precariedad (Oliveira, 2006) tanto para acceder al mercado de trabajo y desempeñarse en condiciones laborales dignas (en términos de salario, contratos, prestaciones y estabilidad), como para ingresar y permanecer en el sistema educativo hasta finalizar sus estudios (Luna y López, 2006).

Teniendo en cuenta que tanto el estudio de la participación en la actividad económica como el análisis de la inserción educativa se enriquecen al considerar a los individuos en el contexto de sus unidades domésticas (García y Pacheco, 2000), y entendiendo que los hogares, en tanto relaciones sociales que operan sobre la demanda de bienes y servicios, la reproducción de la fuerza de trabajo y las relaciones de la vida cotidiana, actúan como mediadores entre el contexto macroeconómico y los individuos en el nivel microsocial, es importante reflexionar sobre la relación entre las capacidades y potencialidades de los individuos para insertarse laboral y educativamente, y las características de composición y estructura de sus hogares de origen.

Los estudios sociodemográficos sobre la familia suelen centrarse en el análisis del hogar como una manera de abordar las formas en que se organizan los grupos domésticos para lograr su subsistencia cotidiana y para reproducirse a través del tiempo. El hogar representa una pequeña colectividad social en la que sus integrantes comparten una identidad (sustentada generalmente en el parentesco) y cierto sentido de solidaridad derivado de una residencia y una economía comunes. Esto supone que los miembros de un hogar no sólo están unidos por lazos de sangre, adopción o alianza, sino que establecen relaciones interdependientes para satisfacer sus necesidades y para asignar y cumplir deberes y responsabilidades en función de sus características demográficas y sociales individuales (Conapo, 2000).

Ahora bien, el estudio de las unidades familiares exige tomar en cuenta como unidades de análisis al conjunto de personas que ocupan en común una vivienda familiar principal o parte de ella, y consumen o comparten los alimentos u otros bienes con cargo a un presupuesto común, es decir, el hogar. 
Por tanto, en este caso la unidad del análisis es el hogar, entendido como una unidad de consumo que comparte la residencia y los recursos para comer, " una persona o grupo de personas, sean parientes o no, que ocupan la totalidad o parte de la vivienda, comparten la comida y satisfacen en común otras necesidades básicas" (Naciones Unidas, 1994). Al considerar el hogar como unidad de análisis tenemos la posibilidad de "examinar los comportamientos de los individuos [...] como actores sociales [...] y los procesos reproductivos como unidades de estudio privilegiadas" (Szasz, 1993: 12). ${ }^{1}$

De esta forma el hogar es entendido como el lugar donde los individuos organizan su reproducción cotidiana y generacional y donde se lleva a efecto la socialización de los nuevos miembros y el reforzamiento de los significados y motivaciones que fundamentan las actividades del grupo (García y Oliveira, 1998). En la misma línea de análisis, otros autores más enfatizan que "la supervivencia de los individuos depende en gran medida de la unidad doméstica, pues constituye la principal defensa frente a la desocupación, el ingreso personal insuficiente, la vejez o la enfermedad" (Margulis, Rendón y Pedrero, 1981: 298).

Uno de los factores determinantes de la composición del hogar es la dinámica demográfica, ya que la posibilidad de convivir o no con parientes depende de quienes se reconocen socialmente como tales, y también de las probabilidades de que éstos sobrevivan en un momento determinado, dados los niveles de fecundidad y mortalidad de la población. De tal forma, la etapa del ciclo vital en que se encuentran los hogares, su número y tamaño, constituyen los principales factores de cambio en la estructura familiar (Goldani, 2001).

Si bien las condiciones socioeconómicas, las nuevas tendencias demográficas y las preferencias por ciertas formas de cohabitación, entre otros factores, influyen en la conformación de los arreglos residenciales, la convivencia en hogares nucleares continúa siendo la forma de vida predominante en México.

¿Cuáles son las consecuencias de las transformaciones y cambios demográficos en la vida familiar? Algunos autores aseguran que a medida que se contrae el tamaño del hogar los ritmos de la vida familiar cambian. Los niños tienen menos hermanos y primos con quienes jugar; las parejas pasan más tiempo haciendo una vida en común sin

${ }^{1}$ El optar por la unidad doméstica como unidad de análisis en esta investigación nos permitirá enfocar la mirada con una perspectiva micro, y además nos posibilitará para buscar la diversidad dentro de los patrones de comportamiento de la población. 
hijos dependientes; hay menos parientes que ayuden a cuidar a los niños pequeños y menos hijos que se hagan cargo de sus padres en la vejez, y ocurren menos eventos (nacimientos, bodas y muertes) que congreguen a las familias (Lloyd y Duffy, 1998; Tuirán, 1993). Asimismo, la reducción de la descendencia ocasiona que las mujeres disminuyan el tiempo que se solía dedicar a la crianza de los hijos, lo cual les abre un espacio para llevar a cabo actividades extradomésticas. Con estas consideraciones se han justificado los estudios que centran el análisis de los hogares en el hecho de que cuenten o no con la presencia de niños y ancianos.

A partir de estas situaciones se considera que un análisis descriptivo de los hogares diferenciados por la variable presencia de jóvenes en el hogar es necesario para enriquecer la investigación que se ha desarrollado hasta el momento en el país, ya que la vida de los jóvenes en sus hogares, cuántos y quiénes son, las características de tales hogares en contraposición con las formaciones sin jóvenes, es un tema relativamente poco analizado. ${ }^{2}$

Para el desarrollo de este trabajo se utilizó el II Conteo de Población y Vivienda 2005 que realizó el Instituto Nacional de Estadística, Geografía e Informática, ya que constituye un insumo que permite la aproximación a la situación de los jóvenes desde una perspectiva estadística que ofrece múltiples posibilidades de análisis, aunque en el presente trabajo se realiza un primer acercamiento exploratorio y descriptivo de la información.

Igualmente, y en tanto el objetivo general del II Conteo es producir información sociodemográfica básica que actualice los datos sobre el tamaño de la población, su composición y distribución territorial, así como de los hogares y las viviendas existentes en el país, contribuye al conocimiento de la realidad nacional y al proceso de programación y diseño de políticas y programas que llevan a cabo las dependencias públicas (INEGI, 2006). Este trabajo toma entonces como insumo la muestra de $10 \%$ del Conteo de Población del año 2005, utilizando la información individual en un primer momento, y su posterior agregación y empate con los datos de los hogares.

${ }^{2}$ De acuerdo con Lenkiewicz (2005), a pesar que en México se vienen realizando investigaciones sobre jóvenes desde hace varias décadas, la reflexión teórica respecto a la categoría juvenil ha sido escasa. Si bien no es el objetivo de este trabajo discutir la suficiencia de los análisis teóricos que se han llevado a cabo, se considera que el actualizar la información disponible sobre la población joven y en ese sentido describirla y caracterizarla, es un insumo que colabora para el enriquecimiento del debate teórico de "lo juvenil". 
El trabajo se centra, por un lado, en el propósito de avanzar en el análisis de los hogares desde una perspectiva sociodemográfica, y por el otro, en la intención de profundizar en esta materia de estudio tomando en cuenta la presencia en los hogares de jóvenes entre 12 y 29 años de edad.

Aquí es necesario hacer un alto para puntualizar que el trabajar con el concepto juventud implica necesariamente establecer los criterios de selección de la población. A este respecto algunos autores sostienen que en la sociedad contemporánea la juventud es más una categoría cultural que una condición biológica, ya que los atributos que se vinculan con esta etapa de la vida parecen haberse movido mucho más allá de los límites biológicos, para convertirse en una ampliamente difundida connotación cultural que los individuos asumen como parte de su personalidad en diferentes etapas de su vida (Melucci, 1996, citado por Rossi, 2005).

Los límites etarios de la juventud se diversifican en función de las concepciones teóricas que se utilicen. En este trabajo se propone una delimitación etaria que no deja de ser esquemática, pero que es necesaria para el análisis de la información. Entonces, se consideran dentro de la población joven las personas comprendidas en el grupo de edad de 12 a 29 años, ${ }^{3}$ y se distinguen a su vez cuatro subgrupos; 12 a 14 años, 15 a 19, 20 a 24 y 25 a 29 años, ya que cada uno de ellos mantiene una relación determinada y específica con el mercado laboral y con el sistema educativo. En este rango de edades se decanta la gran mayoría de los cambios y transiciones de la juventud a la vida adulta: la independencia económica, la formación del hogar propio, la creciente libertad personal, entre otros factores.

El haber optado por considerar jóvenes a hombres y mujeres de 12 a 29 años obedece no sólo al hecho de que son diferentes las relaciones que las personas establecen con el contexto en los distintos momentos de su vida, también a los significados e implicaciones de esas relaciones, muy diversos en razón de la edad de los individuos. En esta consideración de la edad se optó por destacar la perspectiva del curso de vida, que reivindica la edad como representación de las dife-

${ }^{3}$ Se escogió este rango de edad de acuerdo con la concepción clasificatoria del Instituto Mexicano de la Juventud y de las Encuestas Nacionales de Juventud de los años 2000 y 2005. Sin embargo es claro que ser joven no guarda una relación directa con un periodo determinado del ciclo biológico, sino que se trata de una etapa que se encuentra tan determinada por los eventos, prácticas, decisiones y relaciones que se mantienen con el grupo social, como por la pertenencia a un determinado rango de edad. Finalmente, la juventud es una construcción cultural, social e histórica. 
rentes etapas de desarrollo de las personas y como un indicador social que determina sus roles y responsabilidades (Camarena, 2004). Cabe aclarar que la consideración del curso de vida se toma únicamente como recurso para delimitar la edad y no como perspectiva metodológica para el análisis.

De este modo, el objetivo principal del documento es identificar las características más importantes de composición y estructura de los hogares con presencia de jóvenes, en relación con los hogares que no cuentan con población joven, y analizar las diferencias entre ambos hogares a partir de variables como el tamaño promedio del hogar, el tipo del hogar, la posición de parentesco y el nivel de escolaridad. ${ }^{4} \mathrm{La}$ comparación entre ambos tipos de hogares resulta de gran interés porque revela los marcados contrastes que existen en las unidades analizadas en función de la edad de la población que las compone, como se detalla más adelante.

Para ello se ha organizado el trabajo en tres secciones. En la primera se presenta un recuento de las principales características de los hogares y de los jóvenes mexicanos en las últimas décadas. Esta revisión hace posible contextualizar los cambios en los patrones y características de ambas unidades de análisis. En la segunda sección se plantean brevemente las tendencias que se han presentado en relación con la medición de los hogares y los jóvenes, exponiendo el perfil de la población captada en el Conteo y especificando las particularidades de la población joven. Finalmente, en la tercera sección se aporta evidencia estadística reciente que permite ilustrar comparativamente las principales particularidades de los hogares con y sin jóvenes en México, destacando las características más notables en cada uno de ellos.

\section{Sobre los hogares y los jóvenes. Principales características y formas de aproximación}

La estructura y composición de los hogares (la forma en que se inician, la integración de las parejas, el tipo de unión, el nacimiento de los

\footnotetext{
${ }^{4}$ Conviene aclarar que la utilización de tales variables como elementos analíticos obedece a que éstas fueron prácticamente todas las variables sociodemográficas que captó el II Conteo de Población y Vivienda. En este sentido es importante mencionar que si bien existen fuentes de información específicas sobre los jóvenes (como las encuestas de juventud), se privilegió esta fuente de información como una forma de reconocer las posibilidades, alcances y limitaciones del Conteo de Población y Vivienda de 2005.
} 
hijos) y los jóvenes (sus características, la inserción en el mundo "adulto", las transiciones que atraviesan) han sido temas de reflexión y análisis en las ciencias sociales. En tanto el hogar constituye el espacio de desarrollo de las relaciones sociales más diversas, desde las consanguíneas hasta las afectivas y de intercambio económico, y los jóvenes forman parte de un estrato poblacional caracterizado por la pertenencia a un rango específico de edad y condiciones sociohistóricas, es importante analizar la integración de los jóvenes a los hogares y las características de los hogares con población juvenil.

Evidentemente al desarrollar un análisis de este tipo hay que tener en cuenta que tanto los hogares como los jóvenes son unidades de una compleja heterogeneidad. En un país como México, marcado por profundas desigualdades sociales, económicas y regionales, las condiciones de desarrollo de los hogares son diversas. Del mismo modo, si bien en este trabajo se analiza un grupo poblacional de un rango de edad determinado, se parte del supuesto de que este grupo asume una amplia diversidad de prácticas, visiones y valores que determinan que la heterogeneidad sea la característica más destacada de los jóvenes mexicanos.

Existe una multiplicidad de hogares y de formas de ser joven, por lo que al estudiarlos se debe tomar en cuenta la diversidad de contextos en que ambos se ubican. Sin embargo también es importante tener en cuenta algunas consideraciones generales sobre las tendencias, características y cambios de los hogares y los jóvenes en las últimas décadas. El realizar esta rápida revisión permitirá ubicar en mejor medida a la población bajo estudio.

Desde la perspectiva demográfica se encuentra ampliamente consensuado que la transición demográfica ha contribuido a modificar el escenario en el cual se forman y desenvuelven las familias y los individuos, provocando importantes cambios en el tamaño y la composición de los hogares, en la estructura del curso de vida y en las relaciones de género e intergeneracionales en el interior de las unidades domésticas. El aumento de la esperanza de vida ha ocasionado una ampliación del "tiempo familiar", y esto ha propiciado que a menudo convivan en los hogares personas que pertenecen a tres e incluso a cuatro generaciones (Conapo, 2004).

Por otra parte, las transformaciones en las pautas reproductivas han contribuido a modificar las cargas y responsabilidades asociadas a la formación familiar y a reducir el número de años que se dedican a la crianza y cuidado de los hijos, creando condiciones favorables para 
que las personas, en particular las mujeres, se propongan otras metas vinculadas con su desarrollo personal. Estas transformaciones, sin embargo, han tenido lugar de manera desigual en los distintos grupos sociales y en las diversas regiones del país, situación que también ha sido extensamente analizada y debatida (Conapo, 2004).

Además de los cambios en la mortalidad y la fecundidad, las transformaciones en la intensidad y el calendario de las pautas de nupcialidad y de disolución conyugal (viudez, separación o divorcio) igualmente han contribuido a modificar la estructura del curso de vida. La evidencia disponible indica que el índice de rupturas conyugales se ha incrementado entre las mujeres de las generaciones más recientes, entre las que se casan a edad temprana y entre quienes transitan por los primeros años del matrimonio. En este proceso la viudez ha cedido su lugar a la separación y el divorcio como modalidades predominantes de disolución conyugal. Estas tendencias inciden en las trayectorias de vida de los cónyuges y los hijos y da lugar a formas de vida más complejas y a una gama de arreglos familiares más amplios, entre los que destaca la formación de arreglos residenciales de personas que viven solas o bien de hogares monoparentales (Conapo, 2004).

En México existe una extensa tradición de estudios sobre la familia que parten de diversas disciplinas y siguen distintos abordajes teórico metodológicos, lo que ha brindado la posibilidad de contar con información sobre el tamaño y la estructura de los grupos familiares; sobre la influencia de las relaciones de parentesco en la conformación de élites nacionales, regionales y locales; sobre la situación de los niños y de las mujeres en la sociedad y en el hogar; y sobre el efecto de las migraciones y de las crisis económicas en la organización doméstica, entre otros aspectos (Gonzalbo, 1995, citado por López Ramírez, 2004).

En las últimas décadas los hogares mexicanos han venido conformando un nuevo perfil, de manera que en la actualidad es posible distinguir cinco grandes tendencias a las que se dirigen (López Ramírez, 2004):

1) la reducción de su tamaño;

2) la coexistencia de diversos tipos de arreglos residenciales;

3) el aumento de la proporción de unidades domésticas encabezadas por mujeres;

4) el "envejecimiento" de los hogares;

5) la mayor participación económica de las mujeres en el mercado laboral. 
Los efectos de la inercia demográfica han ocasionado un incremento acelerado del número de personas en edades productivas y reproductivas, de acuerdo con un diagnóstico del Consejo Nacional de Población:

Como consecuencia, el número de hogares se ha incrementado notablemente en los últimos 35 años, pasando de 4.8 millones en 1960 a 21.1 millones en 1997. Esto significa que mientras la población pasó de 34.9 a 96.3 millones en el mismo periodo, con una tasa de crecimiento anual de $2.71 \%$, los hogares crecieron a una tasa de 3.1\% [López Ramírez, 2004: 19].

Los hogares mexicanos, además, han experimentado la reducción de su tamaño promedio. En 1976, cuatro de cada diez hogares del país eran pequeños o medianos (es decir, formados por cuatro miembros o menos), condición que en la actualidad abarca a casi seis de cada diez unidades domésticas. En concordancia, la proporción que representan los hogares grandes (cinco o más miembros) dentro del total de hogares del país ha perdido peso al pasar de 60.2 a $40.5 \%$ (Conapo, 2004).

Durante las últimas décadas los hogares mexicanos han experimentado cambios en su composición, de manera que los arreglos familiares se han diversificado. Aun cuando el tipo de hogar más común en el país continúa siendo el nuclear, otros tipos de formaciones familiares (en particular los hogares unipersonales) han ido ganando peso gradualmente; además, los arreglos familiares nucleares han experimentado ciertas transformaciones en su interior.

Entre 1976 y 2004 los arreglos familiares de tipo nuclear han pasado de 71.0 a $67.6 \%$ del total de hogares, y dentro de ellos los conformados por la pareja con hijos solteros (tipo nuclear conyugal) representan la organización familiar predominante: tres cuartas partes. A la par, la proporción de hogares nucleares que sólo cuentan con uno de los miembros de la pareja (nucleares monoparentales) ha ido incrementándose ligera pero sistemáticamente, al igual que la de los integrados por una pareja sin hijos.

El peso relativo de los arreglos residenciales extensos (integrados por un hogar nuclear, con uno o ambos miembros de la pareja, y una o más personas emparentadas con el jefe) dentro del total de unidades domésticas, se ha mantenido prácticamente igual durante las últimas décadas. Sin embargo una tipología más desagregada permite observar 
que dentro de este tipo de hogares predominan los arreglos donde conviven la pareja con hijos y otros parientes (hogares ampliados), que en 2004 representan 21.2\% del total de hogares, aunque estos arreglos hayan ido perdiendo peso en favor de los integrados por el jefe con hijos solteros y otros parientes (hogares compuestos), que son $3.6 \%$ del total (Conapo, 2004).

En la actualidad los hogares denominados "no familiares" son más comunes en la sociedad que hace poco más de dos décadas. En 1976 este tipo de arreglos comprendía $4.8 \%$ del total de hogares del país, para 2000 había alcanzado casi $7 \%$, y en la actualidad representa $7.6 \%$ del total (Conapo, 2004). Este incremento se debe a que los hogares formados por una persona (hogares unipersonales) han aumentado su peso relativo de $4.2 \%$ del total de unidades domésticas del país en 1976 a $6.8 \%$ en 2004 (Conapo, 2004).

A pesar de la menor preponderancia de hogares de jefatura femenina en México (en comparación con otros países de la región), se trata de unidades que integran un contingente importante en el conjunto de hogares del país (González de la Rocha, 1997: 7).

Otra tendencia importante en el cambio de los hogares es el envejecimiento de la población, como bien puede apreciarse en la gráfica 1. Esa tendencia se ha acentuado en los últimos años y se presenta en forma más marcada entre las mujeres, como puede observarse en las gráficas 2 y 3.

$\mathrm{Al}$ respecto algunos autores plantean que "En nuestro país, durante la segunda mitad del siglo Xx el interés central de la demografía fue el rápido incremento de la población; hoy, al iniciar el siglo XXI, la atención se encuentra en el proceso de envejecimiento de la población" (Ordorica, 2001).

Finalmente, entre las grandes tendencias que pueden identificarse en las transformaciones acontecidas en los hogares, la cada vez mayor participación de las mujeres en el mercado de trabajo constituye, según diversos autores, una estrategia que asegura la reproducción cotidiana y generacional de los integrantes del hogar, fundamentalmente en contextos y situaciones de crisis y reestructuración económica (López Ramírez, 2004).

Por otra parte, los cambios en los patrones de las pautas reproductivas, unidos con los cambios económicos y los procesos de transformaciones estructurales de la economía, han generado condiciones más convenientes y propicias para la participación de la mujer en el trabajo extradoméstico (García y Oliveira, 1998). 


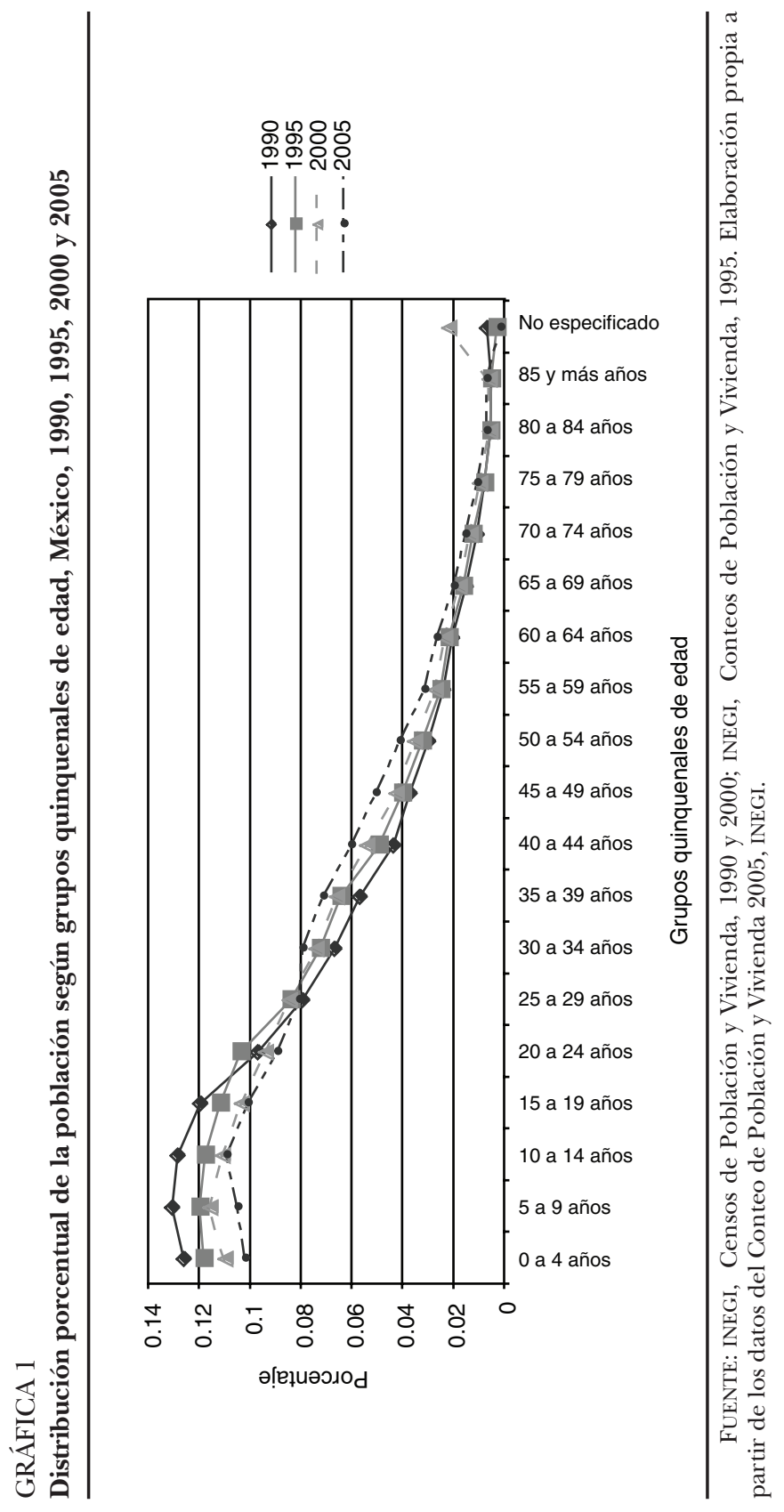




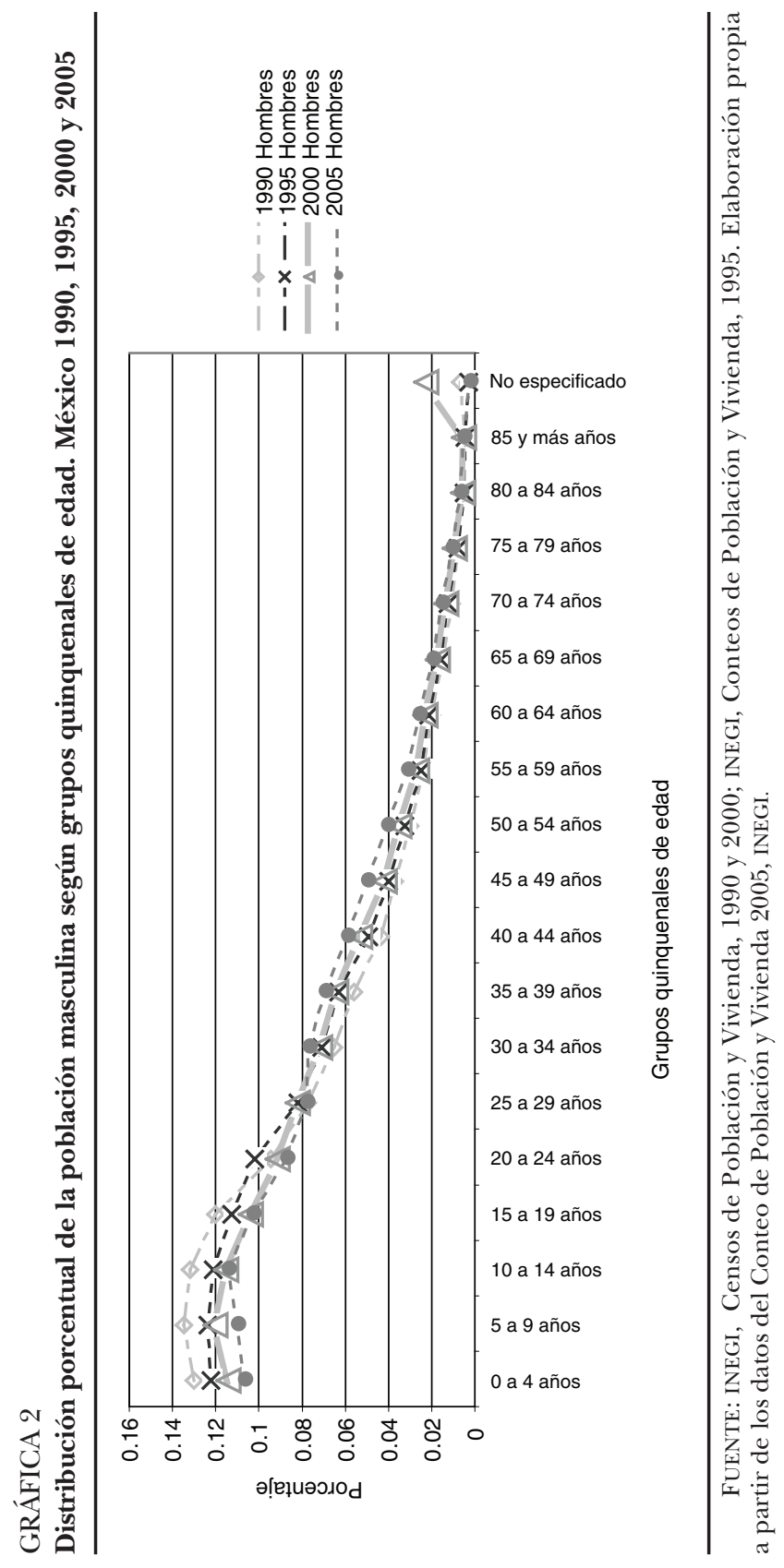




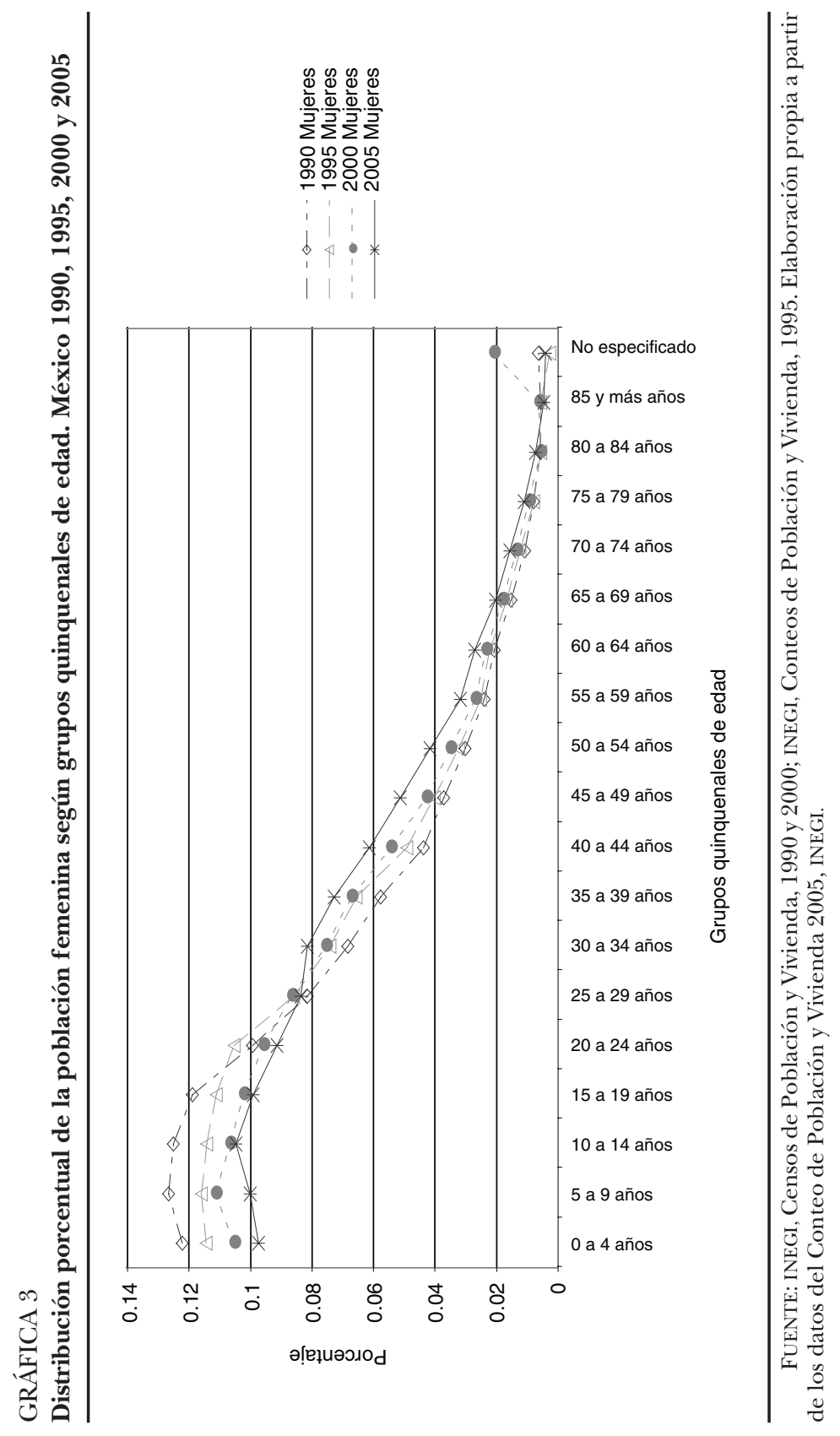


Al mismo tiempo, la influencia de la composición del hogar en las actividades y condiciones de vida de los jóvenes ha ido modificándose en los distintos periodos. Así, durante la década de los setenta se consideraba que la ausencia del padre generaba efectos sumamente negativos sobre los hijos, ya que las madres que quedaban solas contaban con menos recursos económicos. Esta perspectiva fue criticada en la siguiente década por considerar que "el problema de las familias de madre sola no radica en su estructura, sino en el hecho de que estas familias son más pobres y discriminadas por motivos raciales que las familias de padre y madre" (Mier y Terán y Rabell, 2004: 136).

De acuerdo con McLanahan (1997, citado por Mier y Terán y Rabell, 2004) el efecto de los diferentes tipos de convivencia dependerá del indicador que se utilice en la medición; el número de años de escuela, los problemas de comportamiento, el embarazo adolescente, las calificaciones, entre otros.

Así, la discusión sobre la relación entre la estructura del hogar y las condiciones de vida de los jóvenes enriquece la mirada razonada y metódica del hogar como unidad de análisis, al tiempo que evidencia la necesidad de contextualizar a los individuos en sus grupos de pertenencia para discutir la forma en que se insertan en los mercados laborales y educativos. Las investigaciones en este campo se han centrado en los recursos de los que dispone la familia y en la forma en que esos recursos se distribuyen de acuerdo con la estructura de la unidad familiar.

En este sentido, el esbozar el perfil de los hogares con jóvenes en el México actual tiene la utilidad de contribuir como un instrumento diagnóstico a partir del cual se podrán discutir las repercusiones que en las condiciones de vida, trabajo y estudio tienen las características de sus hogares de origen. Si efectivamente es cierto que "Con elevada frecuencia las oportunidades de desarrollo y crecimiento son muy limitadas para sectores importantes de los jóvenes, dado que recaen sobre ellos, desde edades tempranas, responsabilidades y cargas de trabajo no siempre reconocidas y valoradas" (Camarena, 2004: 90) es indispensable identificar las peculiaridades de los hogares y las ventajas y desventajas comparativas de las unidades con y sin jóvenes, tanto para el diseño de políticas públicas, como para avanzar en la investigación académica relacionada con la situación de los jóvenes.

Lo anterior se vuelve indispensable si se toma en cuenta que los jóvenes tienen diferentes formas de reaccionar ante lo que perciben como ausencia de opciones para mejorar sus situaciones de bienestar, 
y una de estas alternativas podría ser abandonar su lugar de origen en busca de condiciones más favorables.

$\mathrm{Al}$ contextualizar estos cambios y tendencias se puede observar el hogar como una entidad intermedia entre los jóvenes y el entorno social en que se ubican. El hogar actúa como un eje articulador de lo individual y lo social.

\section{Las cifras sobre los hogares y los jóvenes. Panorama general}

De acuerdo con datos de la CEPAL (2000), durante la segunda mitad del siglo Xx, y con grandes variaciones entre los países (derivadas de la heterogeneidad de la transición demográfica), la proporción de jóvenes de 15 a 29 años dentro de la población total llegó a su máximo (28.5\% en 1990). Si bien la baja de la fecundidad impulsará el descenso de esta proporción en el futuro hasta llegar a $24.0 \%$ en el año 2020, el tamaño absoluto de la población joven seguirá aumentando en los países de transición moderada e incipiente, y también (por lo menos durante el primer decenio del siglo XXI) en aquellos que se encuentran en plena transición, que reúnen el grueso de la población regional. Además de sus efectos sobre la demanda potencial de servicios sociales (básicamente educación y salud), estas tendencias entrañan importantes desafíos tanto para la incorporación de los jóvenes en forma productiva y creativa como para su participación social, política y cultural (CEPAL, 2000: 21).

$\mathrm{Al}$ constatar el considerable peso relativo de los jóvenes surgen diversas interrogantes sobre las ventajas y desventajas de tal situación. Para hacer un balance es preciso tomar en cuenta las características de dicho segmento de la población y los atributos de las estructuras nacionales de oportunidades. Toda evaluación dependerá de las opciones disponibles para los jóvenes y de las orientaciones de valor de quienes la efectúen. Enfrentados a sociedades con estructuras sociales relativamente cerradas y mercados de trabajo con escasa capacidad de absorción de empleo, algunos verán en ese alto peso relativo de los jóvenes una amenaza a su estabilidad, y es posible que vean la migración internacional como una válvula de escape a las tensiones sociales que genera una juventud frustrada en sus aspiraciones de movilidad (CEPAL, 2000).

Sin embargo, y a pesar de que los jóvenes mexicanos afrontan desafíos para insertarse en marcos productivos y educativos, la realidad 
de México se contrapone con el escenario de crecimiento de la población de 15 a 29 años que presenta la CEPAL, según la cual la población joven ha comenzado a mostrar tendencias decrecientes en su participación en la estructura por edad.

En México el proceso de transición demográfica ha ocasionado profundas transformaciones en la estructura por edad de la población, la disminución de los nacimientos, la reducción de la proporción de niños, el peso creciente de la población joven y en edad laboral, y la aceleración de la dinámica demográfica de la tercera edad, creando condiciones que obligan a repensar el futuro, planteando nuevos y más complejos desafíos.

En la población de 0 a 4 años y la de 5 a 9 años (edades preescolares y escolares) se hace más evidente la reducción de la fecundidad de los últimos años, ya que el grupo de 0 a 4 años pasa de 10635851 en el año 2000 a 10186243 en 2005, y el grupo de 5 a 9 años disminuye de 11215323 en 2000 a 10511738 en 2005.

También hay tendencia al descenso en otros grupos de edad, como se aprecia en la gráfica 4 . El grupo de población entre 20 y 24 años pasó de 9071134 en el año 2000 a 8964629 en 2005, tendencia similar a la que experimentó el grupo de 25 a 29 años, que disminuyó de 8157743 a 8103352 entre 2000 y 2005, de acuerdo con las cifras del INEGI.

Sin embargo conviene tener en cuenta que a pesar de la disminución de la población de jóvenes entre 12 y 29 años, este grupo aún continuará dominado por la inercia demográfica durante algunos años más y ejercerá una fuerte presión en diversos aspectos de la estructura social, por ejemplo sobre la oferta de educación media superior y superior, sobre el mercado de trabajo, así como sobre el mercado habitacional y los servicios de salud especializados, entre otros varios.

En términos porcentuales la población joven (12 a 29 años) pasó de $34.48 \%$ de la población total de México en 2000, a 32.70\% en el año 2005, y de ésta el grupo más joven, es decir el de 12 a 15 años, fue el único que aumentó sensiblemente en términos porcentuales su participación en la estructura por edad.

En la gráfica 7 se muestra la distribución por edad y sexo de la población estrictamente joven teniendo en cuenta la representación por sexos en los distintos grupos de edad. Como se puede advertir, en las primeras edades la proporción de hombres jóvenes es sensiblemente mayor que la de las mujeres, pero a partir de los 18 años comienza a cambiar la tendencia y la proporción mayor es para las mujeres, y así se mantiene hasta la última edad individual considerada. 


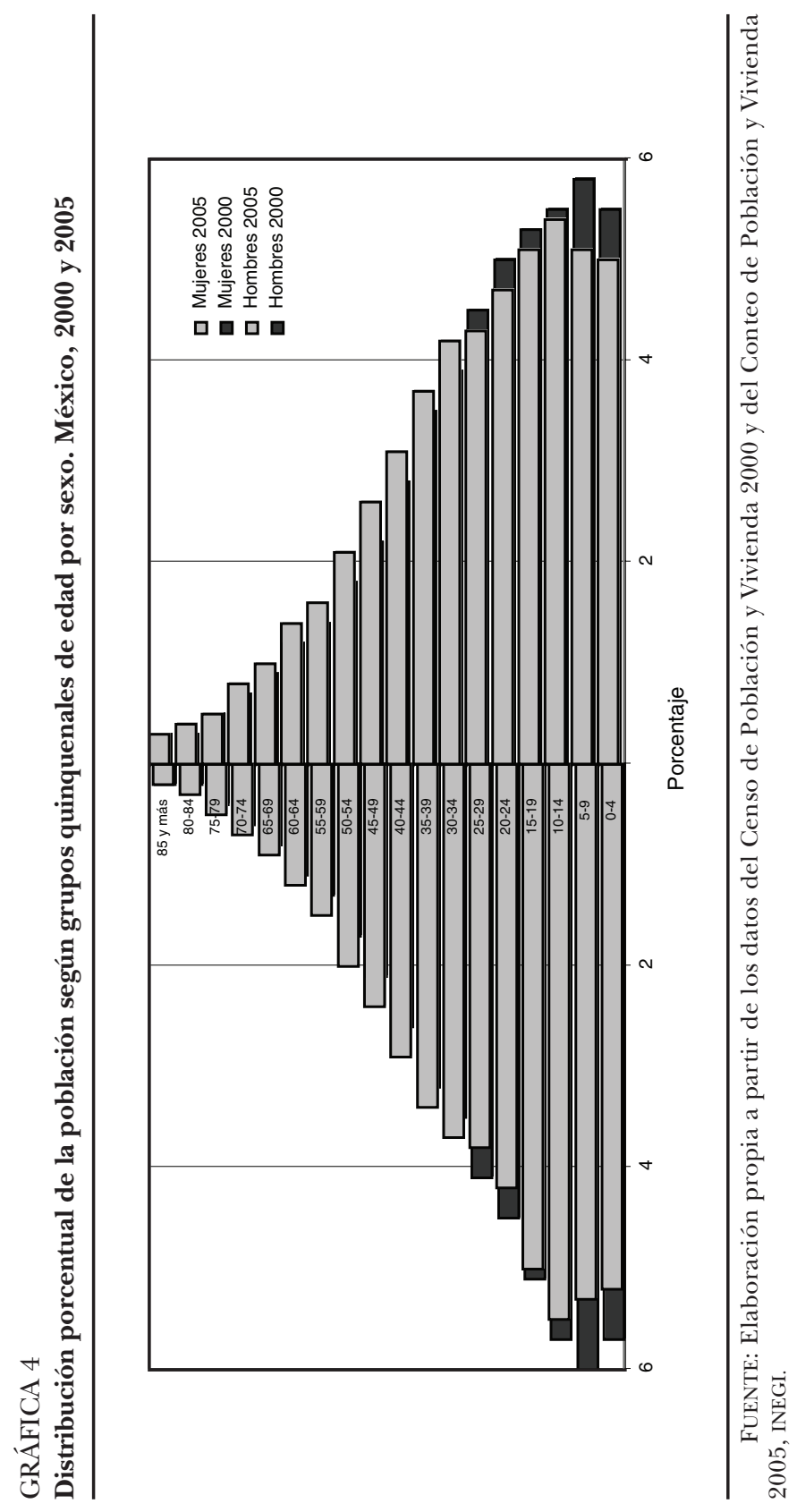




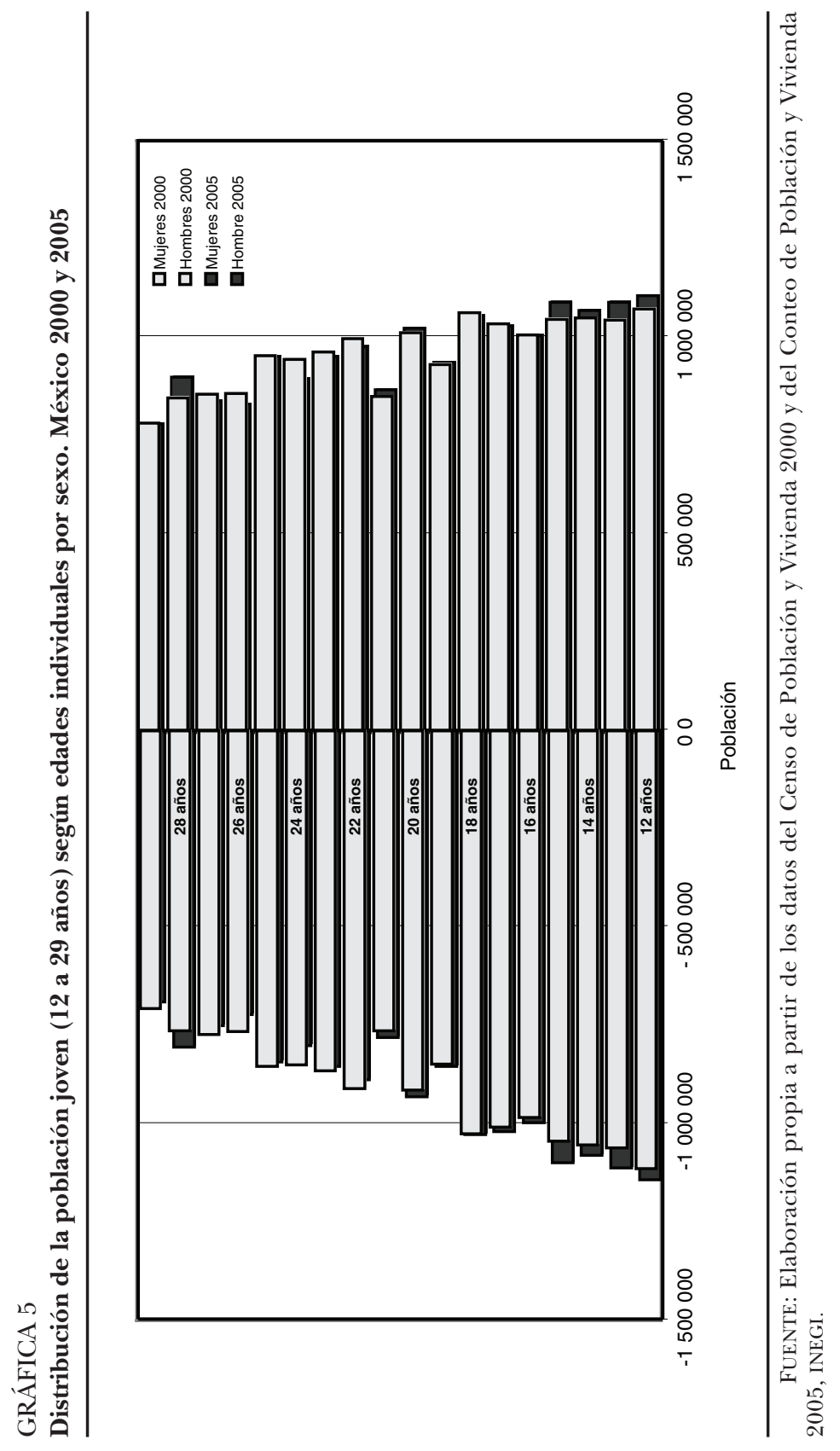




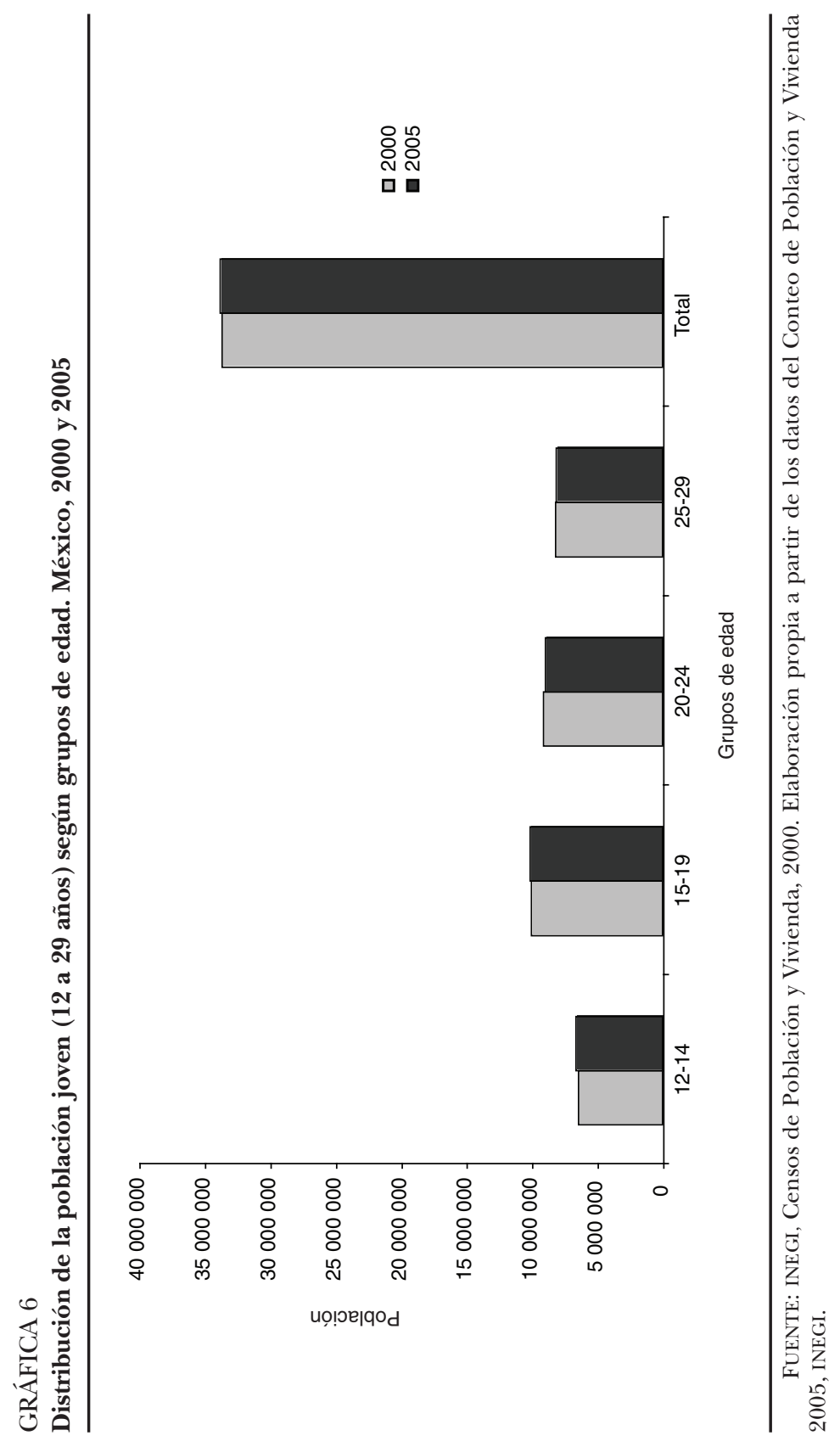




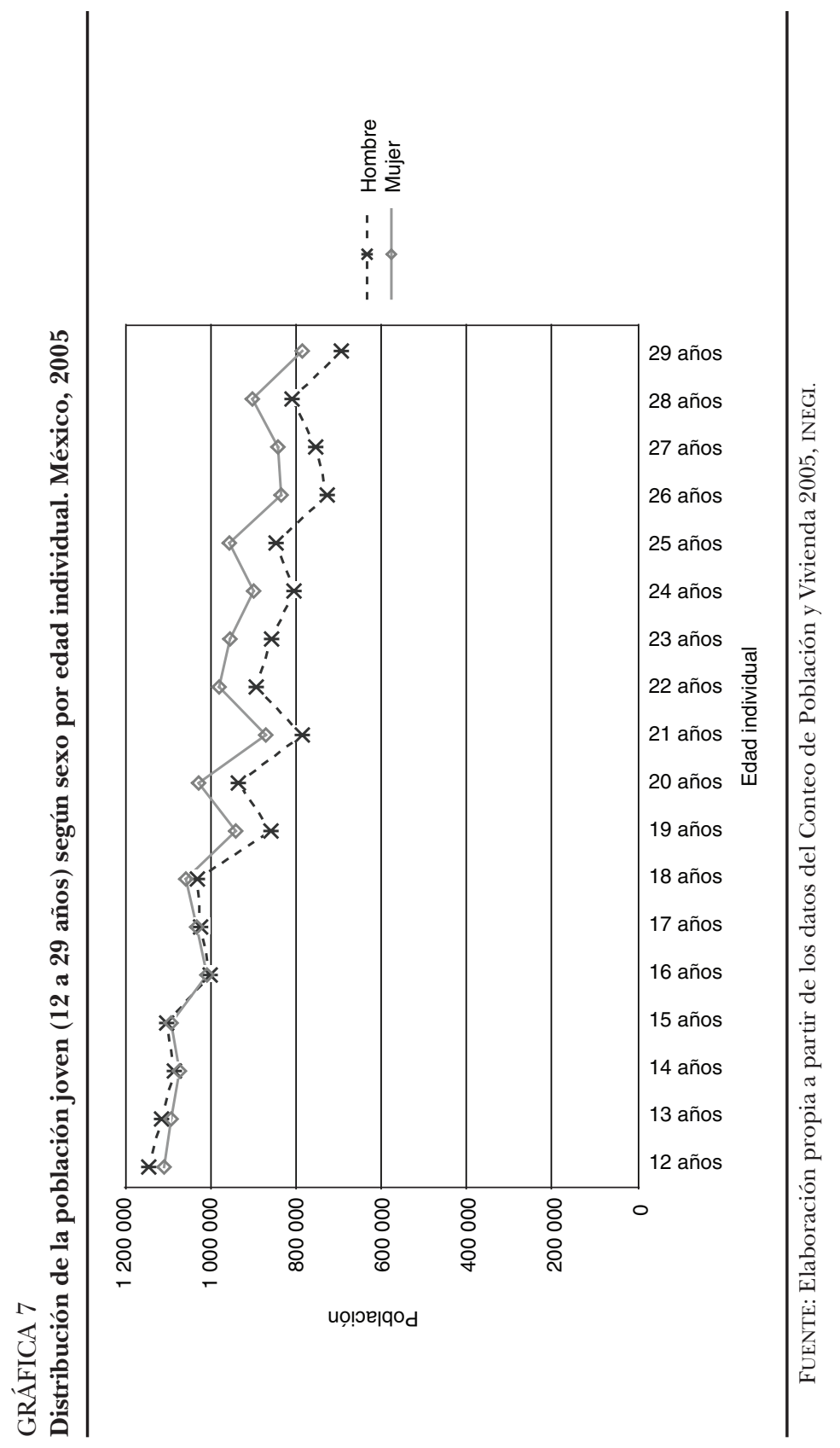


Estos datos son consistentes con la información que proporciona Conapo (2002), ${ }^{5}$ que indica que la población de 65 años o más ha crecido de manera más rápida desde hace 15 años y presenta una tasa con potencial para duplicar su tamaño en menos de dos décadas: el incremento anual asciende a poco más de 200 mil personas y se espera continúe aumentando hasta 788 mil en 2034 para luego disminuir gradualmente hasta 532 mil en 2050. Estos datos confirman el paulatino envejecimiento de la población mexicana, y así lo indican también las cifras del Conteo en relación con el descenso de la población joven.

Al observar la distribución según los grupos de edad específicos relativos a la población total residente en México en 2005 y al total de población joven en el momento del levantamiento, se encuentra que $33.5 \%$ (33 774 976) de la población total del país tiene entre 12 y 29 años de edad, y de ésta $19.5 \%$ tiene entre 12 y 14 años, $29.9 \%$ pertenece al grupo de 15 a 19 años, 26.6\% tiene entre 20 y 24 años de edad, y finalmente $24.1 \%$ pertenece al último grupo definido (25 a 29 años).

En cuanto a la distribución de los hogares según tipo y clase de los mismos, los datos del Conteo indican que $68.3 \%$ de los hogares son nucleares, $22.3 \%$ ampliados, $0.6 \%$ compuestos, $7.5 \%$ unipersonales, y los de corresidentes constituyen $0.5 \%$ del universo considerado.

De acuerdo con las cifras del Conteo de 2005, 65.7\% de la población joven de México reside en hogares nucleares, $31.1 \%$ lo hace en hogares ampliados y $1.0 \%$ en arreglos familiares compuestos. De los que no pertenecen al grupo de 12 a 29 años, $66.4 \%$ vive en hogares nucleares, $29.3 \%$ en ampliados y $0.7 \%$ en hogares compuestos.

Era de esperar respecto a la presencia de jóvenes en hogares unipersonales que únicamente $0.7 \%$ de los jóvenes vive solo, en contraposición con $2.4 \%$ de los que no pertenecen a este grupo de edad. También destaca que para los jóvenes es más común vivir en hogares de corresidentes que para quienes no se encuentran entre los 12 y los 29 años de edad.

Indudablemente el tipo de hogar en que viven los jóvenes guarda una relación directa con los distintos rangos de edad; mientras que los hogares de tipo nuclear van descendiendo a medida que aumenta la edad, una relación inversa se observa en el caso de los hogares unipersonales. Sin embargo el crecimiento de los unipersonales es ciertamente muy pequeño; pasa de $3.9 \%$ de los jóvenes de 12 a 14 años, a $5.0 \%$

${ }^{5}<$ http://www.conapo.gob.mx/prensa/carpetas/carpeta2002_06.htm>. 
CUADRO 1

Distribución de la población joven según grupos seleccionados de edad. México, 2005

\begin{tabular}{|c|c|c|}
\hline Grupos de edad & $\begin{array}{c}\text { Porcentaje } \\
\text { respecto a la población total }\end{array}$ & $\begin{array}{c}\text { Porcentaje } \\
\text { respecto al total de jóvenes }\end{array}$ \\
\hline De 12 a 14 & 6.5 & 19.5 \\
\hline De 15 a 19 & 10.0 & 29.9 \\
\hline De 20 a 24 & 8.9 & 26.6 \\
\hline De 25 a 29 & 8.1 & 24.1 \\
\hline Total & 33.5 & 100.0 \\
\hline
\end{tabular}

Total población joven

33774976

Población total

103263388

FUENTE: Elaboración propia a partir de los datos del II Conteo de Población y Vivienda 2005, INEGI.

CUADRO 2

Distribución de los hogares según tipo y clase. México, 2005

\begin{tabular}{lrc}
\hline Categorías & \multicolumn{1}{c}{ Casos } & Porcentaje \\
\hline Nuclear & 16923515 & 68.3 \\
Ampliado & 5543610 & 22.3 \\
Compuesto & 146341 & 0.6 \\
Unipersonal & 1857791 & 7.5 \\
Corresidente & 119057 & 0.5 \\
Famliar no especificado & 173625 & 0.7 \\
No especificado & 39686 & 0.2 \\
Total & 24803625 & 100.0 \\
\hline
\end{tabular}

FUENTE: Elaboración propia a partir de los datos del II Conteo de Población y Vivienda 2005, INEGI

entre los jóvenes de 25 a 29 años. Los jóvenes mexicanos no son proclives a constituir hogares solos, o al menos no lo son en los rangos etarios considerados.

Una característica importante para el análisis de los hogares es la edad promedio de los mismos. Los datos del II Conteo indican que la edad media de los hogares mexicanos en 2005 es de 33.53 años, casi 6.5 años más que en 2000 (Zúñiga y Gomes, 2002), lo que evidencia 
CUADRO 3

Distribución porcentual de la población joven y no joven según tipo y clase de hogar donde reside. México, 2005

\begin{tabular}{lrc}
\hline Categorías & Jóvenes & No jóvenes \\
\hline Nuclear & 65.7 & 66.4 \\
Ampliado & 31.1 & 29.3 \\
Compuesto & 1.0 & 0.7 \\
Unipersonal & 0.7 & 2.4 \\
Corresidente & 0.5 & 0.2 \\
Familiar no especificado & 0.9 & 0.9 \\
No especificado & 0.1 & 0.1 \\
Total & 100.0 & 100.0 \\
\hline
\end{tabular}

Población total 103263388

FUENTE: Elaboración propia a partir de los datos del II Conteo de Población y Vivienda 2005, INEGI.

una de las características de la situación demográfica mexicana del siglo XXI que se mencionó anteriormente, vinculada con el acelerado envejecimiento de la población y las tasas inéditas del crecimiento demográfico de los adultos mayores.

Como era de esperarse la edad promedio de los hogares que tienen jóvenes desciende a 26.8 años, mientras que la de aquéllos donde no los hay es de 49.5 años. Esta información se relaciona con la etapa del ciclo vital por la que atraviesan los hogares, es decir, quienes cuenten con miembros jóvenes tenderán a estar en una etapa más temprana del ciclo que los que no los tengan.

El Conteo corrobora algunas de las tendencias que se han venido analizando en México en relación con los patrones y cambios del comportamiento demográfico. En primer lugar constata el envejecimiento de la población al evidenciar una baja en la proporción total de jóvenes en el país entre 2000 y 2005 y un incremento de los grupos de edad más avanzada. Del mismo modo confirma la creciente simultaneidad de diversas formas de arreglos residenciales, si bien los hogares nucleares continúan siendo los predominantes. Al igual que la población en su conjunto, la amplia mayoría de los jóvenes reside en hogares nucleares, y un porcentaje muy reducido en hogares de tipo unipersonal. Indudablemente las etapas del ciclo de vida, los procesos de formación educativa y las posibilidades de ingresar al mercado de 


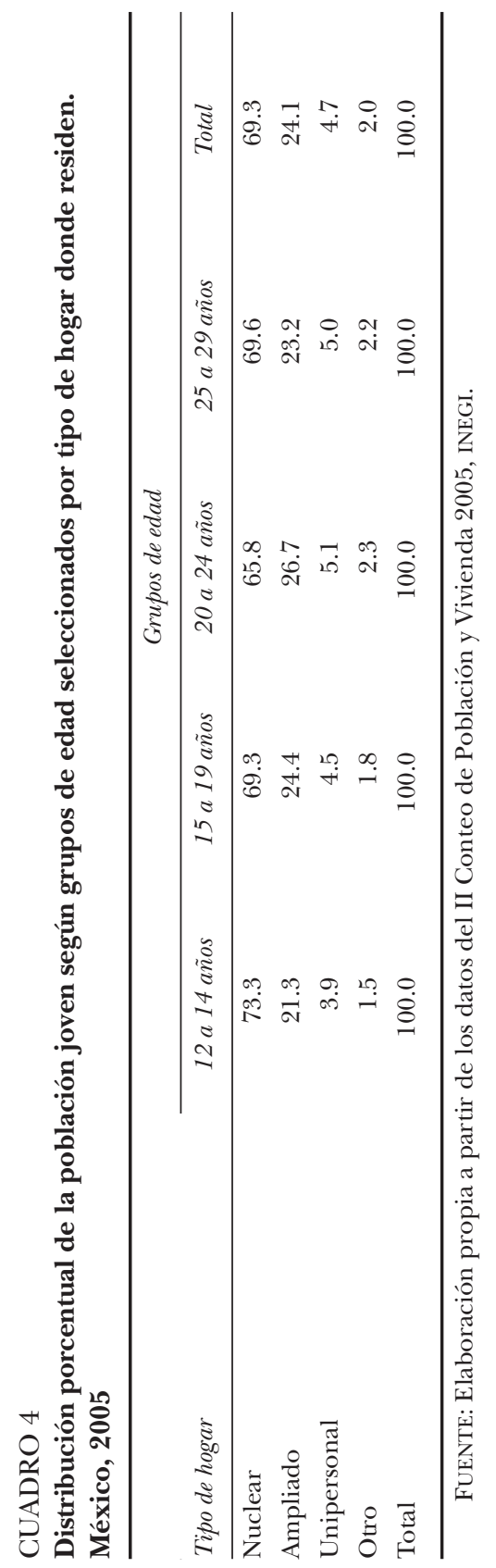


CUADRO 5

Edad media y mediana de los hogares según residan jóvenes o no. México, 2005

\begin{tabular}{lccc}
\hline & Todos & Con jóvenes & Sin jóvenes \\
\hline Media & 33.5 & 26.8 & 49.5 \\
Mediana & 26.8 & 24.5 & 45.5 \\
Número de hogares & 24803625 & 17461752 & 7341873 \\
\hline
\end{tabular}

FUENTE: Elaboración propia a partir de los datos del II Conteo de Población y Vivienda 2005, INEGI.

trabajo, son factores que inciden tanto en la realidad de los jóvenes como en las características de composición de sus hogares.

Pero, ¿de qué jóvenes se trata? Insistentemente se observa que ellos no constituyen un conjunto indiferenciado. ¿Cómo reconocer y analizar la heterogeneidad de esta población? Una de las pocas posibilidades que ofrece el Conteo es distinguir a los jóvenes de acuerdo con la posición de parentesco que ocupan en el hogar, y a partir de ello asumir que han formado un hogar propio o que permanecen en los hogares de origen.

Los datos al respecto indican que entre los de 12 a 14 años prácticamente cuatro de cada diez son nietos y tres de cada diez son hijos. Entre los jóvenes de 15 a 19 años continúan predominando los hijos y nietos, pero ya comienzan a definirse las categorías de jefe y cónyuge con 5.4 y $9 \%$ respectivamente. Los jefes aumentan a $32.2 \%$ entre los jóvenes de 20 a 24 años, rango para el que también ascienden a $34.6 \%$ los cónyuges y a $42.4 \%$ las nueras o yernos. Sin embargo los hijos y nietos no pierden presencia, con proporciones de 23.2 y $17.2 \%$ cada categoría respectivamente. Los jefes y cónyuges constituyen seis de cada diez entre los jóvenes de 25 a 29 años, tres de cada diez son nueras o yernos, los hijos disminuyen a $12.6 \%$ y los nietos a 6.7 por ciento.

Si la plena integración de los jóvenes a la vida adulta y productiva se presenta con la independencia y la autonomía económica y personal, traducida por ejemplo en la conformación de un hogar propio, en México puede observarse en mayor medida esta "emancipación" a partir de los 24 años. Los cambios de las estructuras productivas, sociales e incluso culturales han influido en las posibilidades de inserción de los jóvenes. Por un lado, los datos indican que varias generaciones conviven en un hogar (abuelos y nietos), situación relacionada con la 


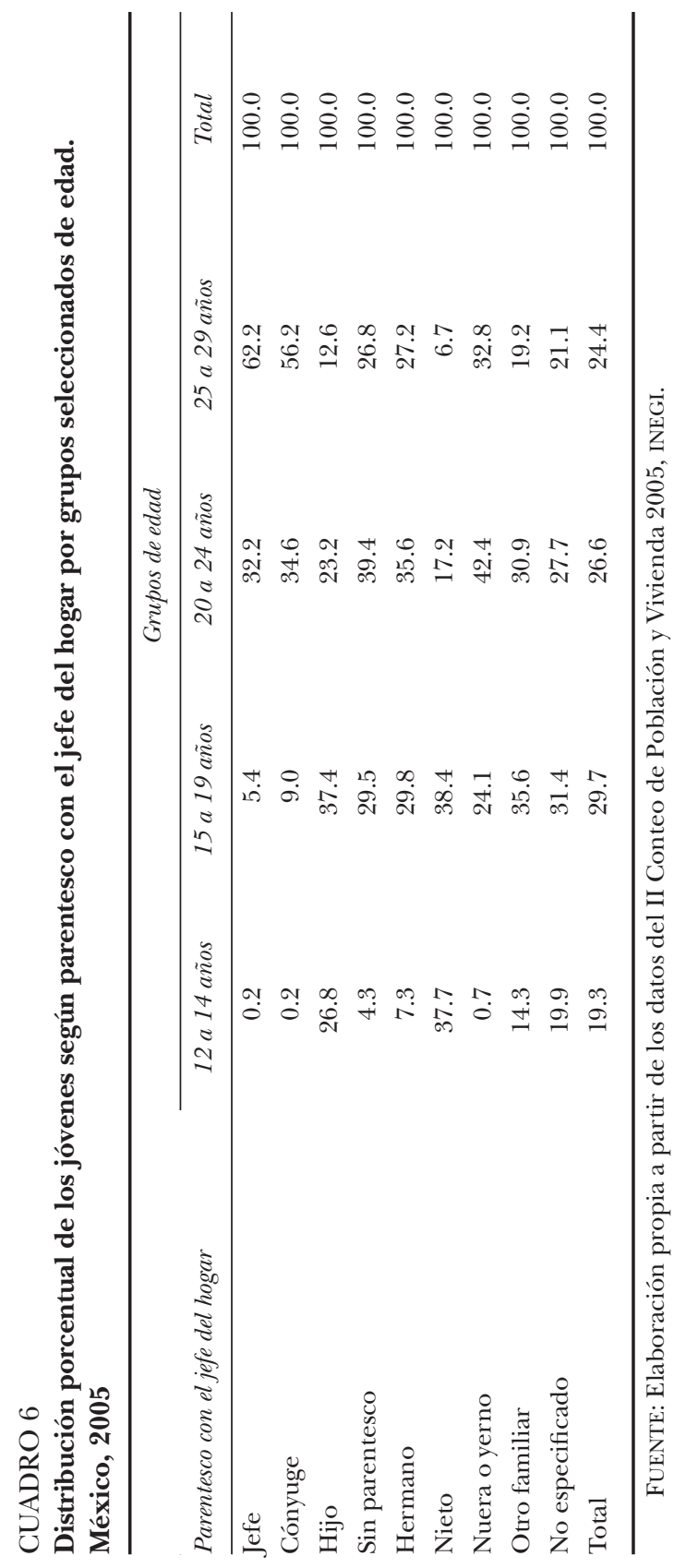


creciente esperanza de vida de la población y con los condicionantes económicos que obstaculizan el acceso a una vivienda propia y distinta de la de origen.

Por otra parte, la permanencia de los jóvenes en sus hogares de origen, y por lo tanto la postergación de la conformación de un hogar propio, puede indicar un ingreso más tardío al mercado laboral, un retraso emancipatorio, e incluso un cambio en los patrones y proyectos de vida que estuvieron vigentes durante mucho tiempo referidos a la inserción en la vida adulta mediante la trayectoria familia-escuelatrabajo.

Esta trayectoria se ha vuelto vacilante; las certezas y seguridades ante el futuro fluctúan, las funciones y posibilidades de trabajo se han modificado, la educación ha transformado sus significados y su utilidad como puerta de entrada al mundo laboral, e inclusive las políticas estatales dirigidas a la familia han sufrido alteraciones. A este conjunto de transformaciones se suman todos los cambios propios del proceso de la juventud: una etapa de búsqueda de significados en la cual la relación con la familia, los vínculos y la posición en el hogar son tan únicos como los propios individuos.

En este sentido la condición juvenil es oscilante, relativa y transitoria. El sujeto actual construye su biografía de modo no lineal, transitando por etapas en las que existe una preeminencia de características generalmente asociadas a la condición de adulto (como por ejemplo la capacidad de sostener económicamente a la familia), mientras en otros momentos se encontrará en una condición juvenil (como estudiante) o donde convivirán ambas (creciente independencia en el plano sociocultural, en convivencia con dependencia económica (Rossi, 2005).

Reconocer este mosaico de valores y contextos multifacéticos es imprescindible. Sería poco atinado no hacerlo. Sin embargo, al realizar el análisis comparativo que se presenta a continuación, el eje vertical tiene que ver con la comparación de los hogares que tienen y no tienen jóvenes, pensando en las posibilidades analíticas de este tipo de trabajos. El supuesto que subyace en todo el análisis es la existencia de tal diversidad. 


\section{Los hogares con y sin jóvenes. Resultados comparativos a partir del Conteo del año 2005}

Para realizar el análisis comparativo de los hogares con y sin jóvenes se seleccionaron muchas de las variables del II Conteo, que se presentan y analizan a continuación y que integran la gran mayoría de las variables demográficas incluidas en éste. Son: la distribución espacial de los hogares en el territorio mexicano, la edad promedio de los hogares, la jefatura del hogar según sexo, el tipo y composición de los hogares, el tamaño promedio de los hogares, las relaciones de parentesco y la escolaridad del jefe del hogar.

Conviene mencionar un primer dato: de la totalidad de los arreglos familiares mexicanos en 2005 prácticamente tres de cada diez (29.6\%) no cuentan con un miembro de entre 12 y 29 años de edad que resida en ellos al hacerse el levantamiento de la información. Del $70.4 \%$ de hogares restantes, $28.5 \%$ tiene un miembro de estas edades, $27.3 \%$ cuenta con dos jóvenes, $9.2 \%$ con 3 jóvenes, y $5.5 \%$ tiene 4 o más miembros entre 12 y 29 años de edad. Estos datos guardan relación con la información que se ha recabado en las encuestas de juventud, en las cuales para el año 2000 no hubo presencia de jóvenes en $33.4 \%$ de los hogares encuestados, proporción que pasó a $31.8 \%$ en la encuesta de 2005 .

¿Cómo se distribuyen los hogares con y sin jóvenes a lo largo del territorio nacional? Por entidad federativa se puede apreciar que $78.3 \%$ de Chiapas cuenta al menos con un miembro joven. Es el estado que tiene mayor proporción de hogares con esta característica, seguido por Tabasco y Tlaxcala, con 74.6 y $74.4 \%$ respectivamente. En el extremo opuesto se encuentra el Distrito Federal, con la proporción más alta de hogares que no tienen miembros en este grupo de edad (35.7\%), seguido por Colima, Nayarit y Tamaulipas con $32 \%$ aproximadamente.

Estos datos confirman las tendencias desarrolladas por los estados en relación con la etapa de la transición demográfica en que se encuentra cada uno. Es de esperar que el Distrito Federal sea el estado que tenga el mayor porcentaje de hogares sin jóvenes, ya que es el que se encuentra en la fase más avanzada de la transición demográfica. Entonces, siendo Chiapas una de las tres entidades que en el año 2000 mostraban las mayores razones de dependencia juvenil (Aparicio, 2002), es evidente que presente el mayor porcentaje de hogares con presencia de jóvenes. 
Otra de las variables de interés en este trabajo es la relacionada con el jefe de hogar, definido por el INEGI (1999) como la persona reconocida como tal por los miembros del hogar, quien puede estar presente o ausente del mismo. Se trata de la "jefatura declarada", y es la que se utilizará en este trabajo. Como lo indican los datos, la distribución de los hogares según el sexo del jefe, muestra que en el país los hogares jefaturados por hombres ascienden a 73.0\%, los jefaturados por mujeres a $19.5 \%$ y en un grupo particular viven personas solas. Así, los hogares donde viven hombres solos son $4.0 \%$ y donde habitan mujeres solas $3.5 \%$ del total.

Del total de hogares con jóvenes $77.7 \%$ tiene un jefe hombre, mientras que en aquéllos sin jóvenes los jefes representan $61.7 \%$; por otro lado, los hogares con una mujer como jefa y donde residen jóvenes ascienden a $21.0 \%$ en comparación con $16.2 \%$ de los hogares sin jóvenes.

Siguiendo en esta línea, el analizar los hogares según su composición permite acercarse de manera general al grado de complejidad de las estructuras domésticas de los mismos. Durante las últimas décadas los hogares mexicanos han experimentado cambios en su composición, de manera que los arreglos familiares se han diversificado. Aun cuando el tipo de hogar más común en el país sigue siendo el nuclear, los hogares no familiares (en particular, los unipersonales) han ganado peso gradualmente; además, los arreglos familiares nucleares han experimentado ciertas transformaciones.

Así, en un primer acercamiento y en función de los hogares con jóvenes se puede decir que $70.5 \%$ son nucleares, $26.2 \%$ son ampliados, $1.4 \%$ son unipersonales y $2.0 \%$ pertenecen a otra categoría. De los que

\section{CUADRO 7}

Distribución porcentual de los hogares según residan o no jóvenes por sexo del jefe del hogar. México, 2005

\begin{tabular}{lrcc}
\hline & Total & Con jóvenes & Sin jóvenes \\
\hline Jefe hombre & 73.0 & 77.7 & 61.7 \\
Jefa mujer & 19.5 & 20.9 & 16.2 \\
Hombre solo & 4.0 & 0.9 & 11.2 \\
Mujer sola & 3.5 & 0.4 & 10.9 \\
Total & 100.0 & 100.0 & 100.0
\end{tabular}

FUENTE: Elaboración propia a partir de los datos del II Conteo de Población y Vivienda 2005, INEGI. 
no cuentan con jóvenes $63.3 \%$ son nucleares, $13.4 \%$ ampliados, $22.1 \%$ unipersonales y $1.1 \%$ se ubican en el grupo de otro tipo de hogar.

Como ya se expuso en este trabajo, la primera transición demográfica tuvo importantes efectos sobre la familia, y sus consecuencias más evidentes fueron el descenso de la fecundidad y la disminución en el tamaño de los hogares. En México los hogares pasaron de un tamaño promedio de cinco miembros por hogar en los ochenta a cuatro en 2005. Al separar los hogares según la presencia o no de jóvenes en ellos, el tamaño medio de los primeros es de 4.6 miembros y el de los segundos de 2.7 integrantes por hogar.

Tales datos estarían evidenciando lo que Arriagada (2004) llama el descenso de los hogares multigeneracionales, aludiendo a un modelo de familia extendida con cada vez menor presencia en los países latinoamericanos, afirmación que para México debe relativizarse.

Es importante analizar la variable tamaño de los hogares como expresión de las transformaciones sociales y económicas que ocurren fuera de la unidad, así como de las transformaciones internas que resultan de una dinámica propia de los eventos ocurridos dentro de tales grupos. Conviene analizarla en relación con otras variables (López et $a l ., 1993)$, como la composición de parentesco y en este caso la presencia o no de jóvenes en los hogares. A este respecto los datos indican que los hogares con jóvenes son más numerosos que los que no los tienen. Así, del total de hogares con jóvenes $12.1 \%$ tienen seis miembros, contra $2.6 \%$ de los que no cuentan con integrantes entre 12 y 29 años.

El análisis del tamaño de los hogares según el tipo muestra que en México $28.0 \%$ del total de hogares nucleares tiene cuatro miembros, de los que no tienen jóvenes $22.4 \%$ tiene esta misma cantidad de integrantes y de los que tienen jóvenes $30.0 \%$ está integrado por cuatro personas. Por otra parte, los hogares ampliados de seis miembros constituyen $17.7 \%$ del total, los que no tienen jóvenes representan $9.1 \%$ y de aquellos que tienen por lo menos un joven, $19.6 \%$ son ampliados de seis miembros.

De acuerdo con la estructura parental de los hogares, éstos presentan una proporción elevada de hijos entre la población de 12 a 29 años, lo que refleja no sólo la joven estructura por edades, sino la permanencia de los hijos en el seno de la familia (López et al., 1993). Algunos datos interesantes se presentan en el cuadro 8, donde se advierte que del total de hogares con jóvenes donde convive más de una generación, en $10.0 \%$ hay nietos del jefe y en $9.6 \%$ hay nietas, a diferencia de los hogares sin jóvenes donde sólo 3.3 y $3.2 \%$ tienen nietos 
y nietas respectivamente. La corresidencia en el mismo hogar de varias generaciones no hace más que poner en evidencia el crecimiento de la informalidad en todos sus aspectos, que además de la inestabilidad en el salario implica privación de recursos, de seguridad social, de salud, educación e integración.

Otro dato que destaca es la presencia de parientes distintos de los del núcleo familiar estricto; así, en los hogares con jóvenes se observa que en un grupo de éstos residen las parejas de los hijos del jefe, y es mayor la proporción de nueras que de yernos, 5.0 y $2.8 \%$ respectivamente. Esta situación refuerza lo expuesto anteriormente acerca de la complejidad que han adquirido los arreglos familiares en los últimos tiempos y la creciente convivencia de varias generaciones en un mismo hogar.

Varias de las cuestiones que pautan el vertiginoso desarrollo de las sociedades actuales se hacen evidentes ante la presencia de actores sociales como los jóvenes, quienes en el recorrido de su proceso de adaptación dejan al descubierto la incertidumbre respecto al lugar que ocupan en este desarrollo social y en los heterogéneos contextos sociales, económicos, políticos y culturales en los que definen y adquieren significado espacios fundamentales de la vida como la pertenencia y la identidad.

En las coyunturas sociales contemporáneas la elaboración del sentimiento de pertenencia implica para los jóvenes tener referentes concretos, tanto dentro de la organización histórica macrosocial como en la microsocial en los hogares y las familias. Por esto las identidades se refrendan mediante el reconocimiento tanto de personas como de espacios (como el hogar). De allí la importancia de recoger las condiciones de vida de los jóvenes y también las características de sus hogares de origen y propios.

Por otro lado y como es bien sabido, el acceso de la población a los servicios educativos es diferencial dependiendo de las condiciones socioeconómicas y de factores demográficos como la edad, el sexo, y la posición en la estructura de parentesco. Con base en la información del II Conteo se puede constatar que el nivel de instrucción de los jefes de hogar es muy limitado, pues la mayor parte se concentra en las categorías "sin instrucción" e "instrucción primaria". Así, en México $46.3 \%$ de los jefes y $56.3 \%$ de las jefas se ubican en estas categorías. Se advierten importantes diferencias por sexo en beneficio de los hombres.

Indudablemente al analizar el tema de la educación hay que tener en cuenta que existe un desajuste entre las condiciones estructurales 
CUADRO 8

Distribución de los miembros del hogar según sean jóvenes o no por parentesco con el jefe del hogar. México, 2005*

\begin{tabular}{lrcc}
\hline & Total & Con jóvenes & Sin jóvenes \\
\hline Cónyuge hombre & 3.8 & 4.0 & 3.4 \\
Cónyuge mujer & 68.5 & 73.3 & 56.9 \\
Hijo & 58.3 & 69.1 & 32.7 \\
Hija & 56.9 & 67.4 & 31.9 \\
Hermano & 1.7 & 1.8 & 1.3 \\
Hermana & 1.9 & 2.0 & 1.8 \\
Nieto & 8.0 & 10.0 & 3.3 \\
Nieta & 7.7 & 9.6 & 3.2 \\
Yerno & 2.3 & 2.8 & 0.9 \\
Nuera & 3.8 & 5.0 & 0.9 \\
Otro hombre & 4.0 & 4.8 & 2.0 \\
Otra mujer & 6.4 & 7.1 & 4.6 \\
No pariente hombre & 0.6 & 0.7 & 0.4 \\
No pariente mujer & 0.5 & 0.6 & 0.3 \\
Empleado doméstico & 0.1 & 0.1 & 0.0 \\
Empleada doméstico & 0.5 & 0.6 & 0.3 \\
\hline
\end{tabular}
diente.

* El cuadro no suma $100.0 \%$ porque los datos se calcularon de manera indepen-

FueNTE: Elaboración propia a partir de los datos del II Conteo de Población y Vivienda 2005, INEGI.

y de oportunidades en la sociedad mexicana que produce una diversificación en la condición de los jóvenes, en sus desempeños, así como en un uso combinado de recursos formales e informales. Al mismo tiempo son evidentes las consecuencias de la desigualdad para la formación de diferencias culturales y para la participación en redes de información, comunicacionales e interculturales diversas.

Tras incorporar en el análisis el rubro hogares con y sin jóvenes se puede observar que las diferencias van en el mismo sentido, y como era de esperarse las generaciones más jóvenes están menos representadas en los niveles educativos más bajos. Según López et al. (1993) esto sugiere su mayor acceso a los servicios educativos.

Sin embargo la educación ha ido perdiendo gradualmente las esperanzas que en ella se depositaban como mecanismo de movilidad social hacia el mercado de trabajo y por lo tanto de la autonomía de 


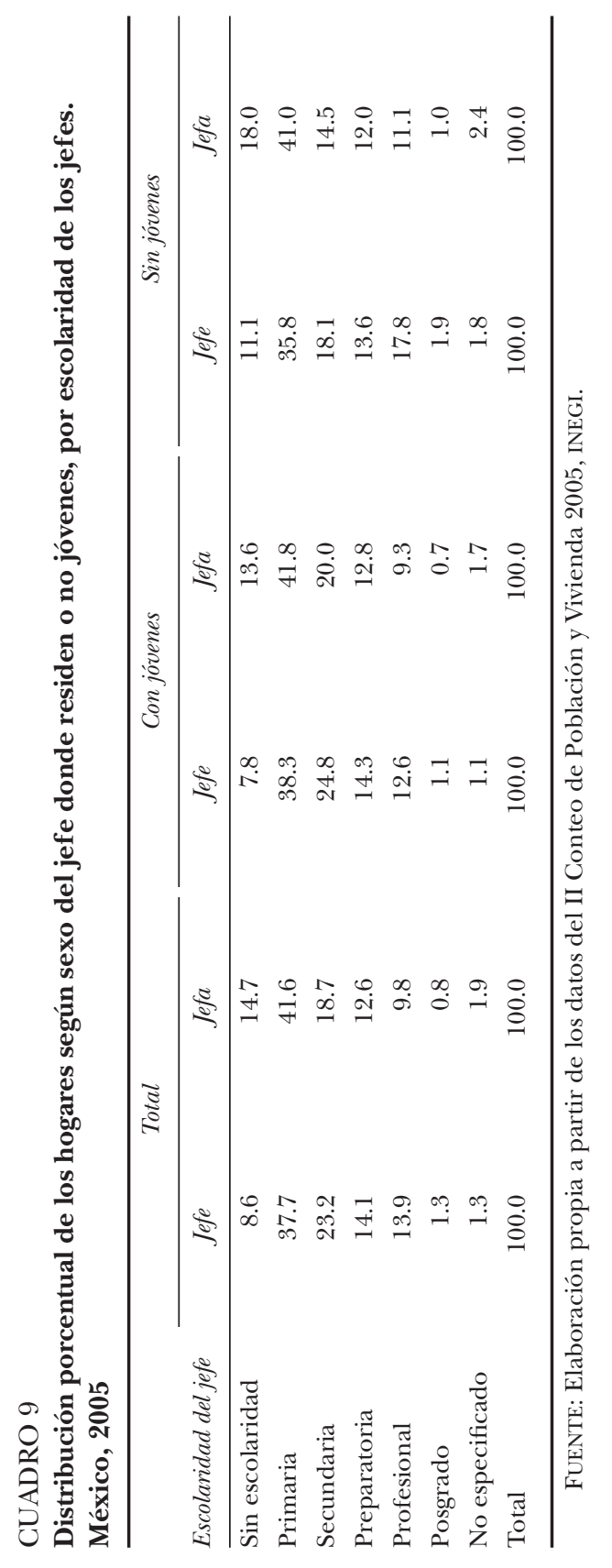


los jóvenes. Lenkiewicz (2005) observa que la escuela fue hasta hace poco tiempo un medio para garantizar la vida futura, y por ende uno de los valores más representativos para la clase media, un símbolo de estatus social.

\section{Observaciones finales}

Esta investigación ha permitido un primer acercamiento exploratorio y descriptivo a la realidad de los hogares que contaban con población joven en México en el año 2005.

Se puede decir que los jóvenes de 12 a 29 años han disminuido su participación en la estructura por edad. El descenso de la población en estos rangos y el incremento en los grupos más avanzados evidencian el proceso de envejecimiento de la sociedad mexicana.

En México aún predominan los hogares nucleares como forma de corresidencia básica, y los jóvenes no constituyen una excepción, ya que viven mayormente en arreglos residenciales de tipo nuclear. Sin embargo, y como pudo observarse, la composición de los hogares sugiere estructuras más complejas, ya que se aprecia que no sólo conviven distintas generaciones, también miembros con diversas relaciones de parentesco.

La convivencia de los jóvenes en hogares nucleares, aunada a la permanencia de los hijos junto a los padres reflejan las dificultades que enfrentan los jóvenes en las sociedades actuales para comenzar sus propios hogares independientemente de sus familias de origen. Al respecto varios estudios han encontrado que el retraso emancipatorio obedece a razones asociadas con el mercado de trabajo y a retrasos y rezagos educativos, así como a situaciones vinculadas con problemas económicos y dificultades para el acceso a la vivienda, entre otras.

La importancia de este tipo de estudios centrados en hogares con miembros jóvenes está en la posibilidad de aportar información estadística para que los estudiosos de temas relacionados con el trabajo y la educación de la población joven orienten convenientemente el diseño de políticas públicas hacia este grupo de la población.

Tal situación adquiere relevancia al tener en cuenta que

el problema de todo grupo joven no es menor si se considera que periodos largos de desempleo erosionan el capital humano con el que cuenta el joven, bloquean una inserción adecuada en una carrera profesional o 
técnica, menoscaban la capacidad productiva inhibiendo la independencia económica, la formación de familia, la integración cabal a la sociedad civil y la asunción de roles como ciudadanos [Abdala, 2002: 225].

De esta forma, lograr la satisfacción de las necesidades y brindar atención a los problemas más relevantes de la población joven constituye un desafío de importancia para el diseño de políticas públicas y para la investigación sociodemográfica. El valor de los resultados que aquí se exponen radica en que confirman, especifican, complementan y amplían el panorama general que presentan los estudios sobre jóvenes en México.

No obstante las limitaciones del análisis de la información, se considera que los datos que arroja la fuente analizada ofrecen un marco de referencia significativo y útil para poner en contexto otras investigaciones relacionadas con el tema y para formular nuevas hipótesis y rutas de investigación. Es en relación con estos dos puntos que se plantean algunas sucintas observaciones finales.

Se parte de la idea de que el Conteo ofrece un conjunto de elementos centrales que es necesario explorar de manera más amplia (por ejemplo, el vínculo entre la composición de los hogares con y sin jóvenes y la disponibilidad de bienes o el índice de hacinamiento) como complemento y contraste de los estudios existentes sobre las condiciones de vida de los jóvenes. ${ }^{6}$ En este sentido se considera que resulta conveniente continuar este análisis estableciendo correlaciones entre algunas de las variables, como los grupos de edad de la población joven y los niveles de escolaridad y disponibilidad de bienes.

Asimismo, los estudios sobre las capacidades y posibilidades laborales y educativas de los jóvenes tienen que ponerse en relación sistemática con el análisis de las características de sus hogares de origen. Tal perspectiva es indispensable no sólo por la evidente relación de influencia recíproca entre las particularidades de composición del hogar y el futuro desempeño laboral y educativo de los jóvenes, sino porque puede aportar claridad en la discusión sobre la influencia de los hogares en las condiciones de vida y en las posibilidades futuras de trabajo y educación de los jóvenes. ¿Qué tanto repercute el hogar en la adquisición de habilidades para el desarrollo formativo y laboral? O en términos sociológicos, ¿en qué medida influye la socialización primaria que los jóvenes reciben en sus hogares en su futuro desempeño como estudiantes y trabajadores?, ¿cómo afectan

\footnotetext{
${ }^{6}$ Por ejemplo véase Mier y Terán y Rabell (2004)
} 
la convivencia con varias generaciones, un mayor o menor hacinamiento, el ciclo de vida de los arreglos residenciales en las expectativas, actitudes y comportamientos de los jóvenes en relación con su vida futura?

De la respuesta que se dé a estas preguntas dependerán el horizonte y los objetivos de muchos programas y políticas públicas dirigidos a esta población.

En términos más generales la pregunta de fondo cuestiona ¿hasta dónde es el hogar el factor determinante de las potencialidades de los jóvenes? Probablemente la respuesta se encuentre en un punto intermedio; no toda la responsabilidad le corresponde al hogar.

Sin embargo, para conocer exactamente cuál es ese punto será necesario avanzar en una investigación que caracterice los hogares y los relacione con las condiciones de inserción de los jóvenes en actividades productivas y educativas.

\section{Bibliografía}

Abdala, Ernesto (2002), "Jóvenes, educación y empleo en América Latina", Papeles de Población, vol. 8, núm. $33<$ http:// papelesdepoblacion.uaemex. $\mathrm{mx} / \mathrm{rev} 33 / \mathrm{pdf} /$ Abdala33.pdf $>$.

Aparicio, Ricardo (2002), "Transición demográfica y vulnerabilidad durante la vejez", en La situación demográfica de México, México, Conapo.

Arriagada, Irma (2004), "Transformaciones sociales y demográficas de las familias latinoamericanas", Papeles de Población, vol. 10, núm. 40, pp. 71-95.

Bruce, Judith et al. (1998), "Introducción”, en La familia en la mira: nuevas perspectivas sobre madres, padres e hijos, Nueva York, Population Council.

Bumpass, Larry (1990), "What's Happening to the Family? Interactions between Demographic and Institutional Change”, Demography, núm. 27, pp. 438498.

Camarena, Rosa María (2004), "Actividades domésticas y extradomésticas de los jóvenes mexicanos", en Marina Ariza y Orlandina de Oliveira (coords.), Imágenes de la familia en el cambio de siglo, México, Instituto de Investigaciones Sociales, Universidad Nacional Autónoma de México.

CEPAL (1993), "Hacia un perfil de la familia actual en Latinoamérica y el Caribe", en Cambios en el perfil de las familias: la experiencia regional, Santiago de Chile, Comisión Económica para América Latina y el Caribe.

CEPAL (1994), "Situación y perspectivas de la familia en América Latina y el Caribe" en Familia y futuro: un programa regional en América Latina y el Caribe, Santiago de Chile, Comisión Económica para América Latina y el Caribe. 
CEPAL (2000), "Juventud, población y desarrollo: problemas, posibilidades y desafíos", Población y Desarrollo, núm. 6, Santiago de Chile, Comisión Económica para América Latina y el Caribe.

Conapo (1995), Programa Nacional de Población 1995-2000, México, Poder Ejecutivo Federal.

Conapo (1998), El perfil sociodemográfico de los hogares en México 1976-1997, México, Consejo Nacional de Población.

Conapo (2000), La situación demográfica de México 2000, México, Consejo Nacional de Población.

Conapo (2004), La situación demográfica de México 2004, México, Consejo Nacional de Población.

Durán, María (1988), "Hogares y familias: dos conceptos en busca de definición”, en Julio Iglesias de Ussel (coord.), Las familias monoparentales, Madrid, Ministerio de Asuntos Sociales.

Echarri, Carlos (1995), "Hogares y familias en México: una aproximación a su análisis mediante encuestas por muestreo”, Estudios Demográficos y Urbanos, vol. 10, núm. 2 (29), pp. 245-293.

Gandini, Luciana (2004) "La exclusión laboral juvenil en Argentina. Propuesta de una tipología para su análisis", Papeles de Población, núm. 42, pp. 153198.

García, Brígida y Orlandina de Oliveira (1998) "Participación femenina en los mercados de trabajo", Revista Trabajo, núm. 1, año 1, México, Universidad Autónoma Metropolitana.

García, Brígida y Edith Pacheco (2000) "Esposas, hijos e hijas en el mercado de trabajo de la Ciudad de México en 1995”, Estudios Demográficos y Urbanos, vol. 15, núm. 1 (43), pp. 35-63.

Goldani, Ana María (2001) "Las familias brasileñas y sus desafíos como factor de protección al final del siglo XX", en Cristina Gomes (comp.), Procesos sociales, población y familia, México, Flacso/Porrúa.

González de la Rocha, Mercedes (1997), "Hogares de jefatura femenina en México", ponencia presentada en la sesión Pobreza, género y desigualdad. Jefatura femenina en hogares urbanos latinoamericanos, XX Congreso Internacional de la Sociedad de Estudios Latinoamericanos (LASA), Guadalajara, México, 16 al 19 de abril.

INEGI (1999), Los hogares con jefatura femenina, Aguascalientes, Instituto Nacional de Estadística, Geografía e Informática.

INEGI (2003), La evolución de los hogares unipersonales, México, Instituto Nacional de Estadística, Geografía e Informática.

INEGI (2006), Conteo de Población 2005, México, Instituto Nacional de Estadística, Geografía e Informática.

Jelín, Elizabeth (1994), "Las relaciones intrafamiliares en América Latina", en Familia y futuro: un programa regional en América Latina y el Caribe, Santiago de Chile, CEPAL. 
Kaztman, Rubén (1995), La medición de las necesidades básicas insatisfechas en los censos de población, Comisión Económica para América Latina y el Caribe, CEPAL, Oficina Montevideo.

Lenkiewicz, Noemí (2005), "Los jóvenes y las familias. Encuentros y tensiones entre filiaciones e identidades", en José Pérez Islas, Mónica Valdez, Madeleine Gauthier y Pierre-Luc Gravel (coords.), Nuevas miradas sobre los jóvenes, México, Instituto Mexicano de la Juventud, pp. 75-85.

López, Paz y Haydea Izazola (1994), El perfil censal de los hogares y las familias en México, México, INEGI/SSA/IIS-UNAM.

López Ramírez, Adriana (2004), El perfil sociodemográfico de los hogares en México, 1976-1997, México, Consejo Nacional de Población.

Lloyd, Cynthia y Niev Duffy (1998), "Familias en transición”, en Judith Bruce, Cynthia Lloyd y Ann Leonard (coords.), La familia en la mira: nuevas perspectivas sobre madres, padres e hijos, Nueva York, Population Council.

Luna, Silvia y Mónica López (2006), "El impacto del nivel de ingreso y tipo de hogar en la formación y uso del tiempo de niños y jóvenes", ponencia presentada en la VIII Reunión Nacional de Investigación Demográfica en México: Repensando la Agenda de Políticas y Acciones en el Ámbito Poblacional, Jalisco, México, 6 al 9 de septiembre.

Margulis, Mario, Teresa Rendón y Mercedes Pedrero (1981), "Fuerza de trabajo y estrategias de supervivencia en una población de origen migratorio: colonias populares de Reynosa”, Demografía y Economía, vol. 15, núm. 3 (47), El Colegio de México.

Mier y Terán, Martha y Cecilia Rabell (2004), "Familia y quehaceres entre los jóvenes”, en Marina Ariza y Orlandina de Oliveira (coords.), Imágenes de la familia en el cambio de siglo, México, Instituto de Investigaciones Sociales, Universidad Nacional Autónoma de México.

Naciones Unidas (1994), Notas para el estudio económico de América Latina 1990, Santiago de Chile.

Oliveira, Orlandina de (1996), "Cambios sociodemográficos y vida familiar en México”, en Rolando Cordera et al. (coords.), Transición mexicana, Memoria del ciclo de mesas redondas, México, UNAM.

Oliveira, Orlandina de (2006), "Jóvenes y precariedad laboral en México", ponencia presentada en la VIII Reunión Nacional de Investigación Demográfica en México: Repensando la Agenda de Políticas y Acciones en el Ámbito Poblacional, Jalisco, México, 6 al 9 de septiembre.

Oliveira, Orlandina de, Marcela Eternod y Paz López (1999), "Familia y género en el análisis sociodemográfico", en Brígida García (coord.), Mujer, género y población en México, México, El Colegio de México.

Ordorica, Manuel (2001), "Supervivencia y muerte en la población mayor. Grandes cambios en las causas de muerte de los mayores", Demos. Carta Demográfica sobre México, México, Instituto de Investigaciones Sociales, UNAM, pp. 10-12.

Partida Bush, Virgilio (2001), "Perspectivas del cambio demográfico. Monto 
y estructura de la población en el año 2000 y perspectivas en el 2050", Demos. Carta Demográfica sobre México, México, Instituto de Investigaciones Sociales, UNAM.

Rossi, Federico (2005), "La condición juvenil ante las transformaciones de la sociedad”, en Diálogos, Propuestas, Historias para una Ciudadanía Mundial, enero-febrero <http://base.d-p-h,info/es/fiches/dph/fiche-dph$6876, \mathrm{html}>$.

Tuirán, Rodolfo (1993), "Vivir en familia: hogares y estructura familiar en México, 1976-1987”, Comercio Exterior, vol. 43, núm. 7, pp. 662-676.

Szasz, Ivonne (1993), Migración temporal en Malinalco. La agricultura de subsistencia en tiempos de crisis, México, El Colegio de México/El Colegio Mexiquense.

Zúñiga, Elena y Cristina Gomes (2002), "Pobreza, curso de vida y envejecimiento poblacional en México", en La situación demográfica de México, México, Conapo. 